\title{
WEIGHTED COMPOSITION OPERATORS FROM WEIGHTED-TYPE SPACES TO ZYGMUND-TYPE SPACES
}

\author{
XIANGLING ZHU
}

Abstract. Some criteria for the boundedness and the compactness of weighted composition operators from weighted-type spaces into Zygmund-type spaces are given in this paper. Moreover, we give some estimates for the essential norm of these operators.

Mathematics subject classification (2010): 30H99, 47B33.

Keywords and phrases: Weighted-type space, Zygmund-type space, essential norm, weighted composition operator.

\section{REFERENCES}

[1] B. Choe, H. Koo And W. Smith, Composition operators on small spaces, Integral Equations Oper. Theory 56 (2006), 357-380.

[2] K. Esmaeili And M. M. LindströM, Weighted composition operators between Zygmund type spaces and their essential norms, Integral Equations Oper. Theory 75 (2013), 473-490.

[3] O. Hyvärinen, M. Kemppainen, M. Lindström, A. RAutio And E. SAUKKo, The essential norm of weighted composition operators on weighted Banach spaces of analytic functions, Integral Equations Oper. Theory 72 (2012), 151-157.

[4] O. HYVÄRINEN AND M. LINDSTRÖM, Estimates of essential norm of weighted composition operators between Bloch-type spaces, J. Math. Anal. Appl. 393 (2012), 38-44.

[5] S. Li And S. Stević, Volterra type operators on Zygmund spaces, J. Ineq. Appl. Volume 2007, Article ID 32124, (2007), 10 pages.

[6] S. Li AND S. STEVIĆ, Weighted composition operators from $\alpha$-Bloch space to $H^{\infty}$ on the polydisk, Numer. Funct. Anal. Optim. 28 (7) (2007), 911-925.

[7] S. Li AND S. STEVIĆ, Weighted composition operators from Bergman-type spaces into Bloch spaces, Proc. Indian Acad. Sci. Math. Sci. 117 (3) (2007), 371-385.

[8] S. Li AND S. STEVIĆ, Weighted composition operators from $H^{\infty}$ to the Bloch space on the polydisc, Abstr. Appl. Anal. Vol. 2007, Article ID 48478, (2007), 12 pages.

[9] S. Li AND S. STEVIĆ, Generalized composition operators on Zygmund spaces and Bloch type spaces, J. Math. Anal. Appl. 338 (2008), 1282-1295.

[10] S. Li AND S. STEVIĆ, Weighted composition operators from Zygmund spaces into Bloch spaces, Appl. Math. Comput. 206 (2008), 825-831.

[11] S. Li AND S. STEVIĆ, Products of composition and differentiation operators from Zygmund spaces to Bloch spaces and Bers spaces, Appl. Math. Comput. 217 (2010), 3144-3154.

[12] B. MACCLUER AND R. ZHAO, Essential norm of weighted composition operators between Bloch-type spaces, Rocky. Mountain J. Math. 33 (2003), 1437-1458.

[13] K. MAdigan And A. Matheson, Compact composition operators on the Bloch space, Trans. Amer. Math. Soc. 347 (1995), 2679-2687.

[14] A. Montes-RodrigueZ, The essential norm of composition operators on the Bloch space, Pacific J. Math. 188 (1999), 339-351.

[15] A. Montes-RodrigueZ, Weighed composition operators on weighted Banach spaces of analytic functions, J. London Math. Soc. 61 (2000), 872-884.

[16] S. Ohno, K. Stroethoff And R. Zhao, Weighted composition operators between Bloch-type spaces, Rocky Mountain J. Math. 33 (2003), 191-215. 
[17] S. STEVIĆ, Weighted composition operators between mixed norm spaces and $H_{\alpha}^{\infty}$ spaces in the unit ball, J. Ineq. Appl. Vol. 2007, Article ID 28629, (2007), 9 pages.

[18] S. STEVIĆ, Essential norms of weighted composition operators from the $\alpha$-Bloch space to a weightedtype space on the unit ball, Abstr. Appl. Anal. Vol. 2008, Article ID 279691, (2008), 11 pages.

[19] S. STEVIĆ, Norm and essential norm of composition followed by differentiation from $\alpha$-Bloch spaces to $H_{\mu}^{\infty}$, Appl. Math. Comput. 207 (2009), 225-229.

[20] S. STEVIĆ, On an integral operator from the Zygmund space to the Bloch-type space on the unit ball, Glasg. J. Math. 51 (2009), 275-287.

[21] S. STEviĆ, On an integral-type operator from logarithmic Bloch-type and mixed-norm spaces to Bloch-type spaces, Nonlinear Anal. TMA 71 (2009), 6323-6342.

[22] S. STEVIĆ, Weighted composition operators from weighted Bergman spaces to weighted-type spaces on the unit ball, Appl. Math. Comput. 212 (2009), 499-504.

[23] S. STEVIĆ, Weighted differentiation composition operators from mixed-norm spaces to weighted-type spaces, Appl. Math. Comput. 211 (2009), 222-233.

[24] S. STEVIĆ, On operator $P_{\varphi}^{g}$ from the logarithmic Bloch-type space to the mixed-norm space on unit ball, Appl. Math. Comput. 215 (2010), 4248-4255.

[25] S. STEVIć, Weighted differentiation composition operators from $H^{\infty}$ and Bloch spaces to $n$th weigthed-type spaces on the unit disk, Appl. Math. Comput. 216 (2010), 3634-3641.

[26] S. STEVIĆ AND A. K. ShARMA, Weighted composition operators between growth spaces of the upper half-plane, Util. Math. 84 (2011), 265-272.

[27] S. STEVIĆ AND A. K. SHARMA, Weighted composition operators between Hardy and growth spaces on the upper half-plane, Appl. Math. Comput. 217 (2011), 4928-4934.

[28] S. SteVić, Z. Zhou And R. Chen, Weighted composition operators between Bloch type spaces in the polydisc, Sb. Math. 201 (1-2) (2010), 289-319.

[29] S. STEVIĆ AND S. I. UEKI, Integral-type operators acting between weighted-type spaces on the unit ball, Appl. Math. Comput. 215 (2009), 2464-2471.

[30] M. TJANI, Compact composition operators on some Möbius invariant Banach spaces, $\mathrm{PhD}$ dissertation, Michigan State University, 1996.

[31] H. Wulan, D. Zheng And K. Zhu, Compact composition operators on BMOA and the Bloch space, Proc. Amer. Math. Soc. 137 (2009), 3861-3868.

[32] W. YANG, Weighted composition operators from Bloch-type spaces to weighted-type spaces, Ars Combin. 92 (2009), 415-423.

[33] Y. YU AND Y. LiU, Weighted differentiation composition operators from $H^{\infty}$ to Zygmund spaces, Integ. Trans. Spec. Funct. 22 (2011), 507-520.

[34] R. ZHAO, Essential norms of composition operators between Bloch type spaces, Proc. Amer. Math. Soc. 138 (2010), 2537-2546.

[35] K. ZHU, Operator Theory in Function Spaces, Marcel Dekker, New York and Basel, 1990.

[36] X. ZHU, Generalized weighted composition operators from Bloch spaces into Bers-type spaces, Filomat 26 (2012), 1163-1169.

[37] X. ZHU, Generalized weighted composition operators from Bers-type spaces to Bloch-type spaces, Math. Ineq. Appl. 17 (2014), 187-195. 